\title{
A comparison of ground-based methods for estimating canopy closure for use in phenology research
}

\author{
Smith, AM
}

http://hdl.handle.net/10026.1/10822

10.1016/j.agrformet.2018.01.002

Agricultural and Forest Meteorology

Elsevier Masson

All content in PEARL is protected by copyright law. Author manuscripts are made available in accordance with publisher policies. Please cite only the published version using the details provided on the item record or document. In the absence of an open licence (e.g. Creative Commons), permissions for further reuse of content should be sought from the publisher or author. 


\section{A comparison of ground-based methods for 2 estimating canopy closure for use in phenology 3 research}

4

5 Alison M. Smith1,* \& Paul M. Ramsay ${ }^{1}$

$6{ }^{1}$ School of Biological and Marine Sciences, University of Plymouth, Plymouth, PL4 8AA, 7 UK

$8{ }^{*}$ Corresponding author: School of Biological and Marine Sciences, University of

9 Plymouth, Plymouth, PL4 8AA, UK; alison.smith@plymouth.ac.uk; tel. +44-175210584600.

11 Key words: phenology, canopy openness, hemispherical photography, fisheye 12 photography, citizen science 


\section{A comparison of ground-based methods for estimating canopy closure for use in phenology 16 research}

17

\section{Abstract}

Climate change is influencing tree phenology, causing earlier and more prolonged canopy closure in temperate forests. Canopy closure is closely associated with understorey light, so shifts in its timing have wide-reaching consequences for ecological processes in the understorey. Widespread monitoring of forest canopies through time is needed to understand changes in light availability during spring in particular. Canopy openness, derived from hemispherical photography, has frequently been used as a proxy for understorey light. However, hemispherical photography is relatively resource intensive, so we tested a range of inexpensive alternatives for monitoring variability in canopy closure (visual estimation, canopy scope, smartphone photography, smartphone photography with fisheye attachment; and image analysis with specialist hemispherical photography software or with simpler, open access image analysis software).

Smartphone photography with an inexpensive fisheye lens attachment proved the most reliable estimator of canopy closure. We found no significant difference in canopy estimations from three widely-owned smartphone models with differing resolutions and fields of view, and no significant effect of camera operator on the results. ImageJ, a free image analysis software, detected canopy variability in a similar way to HemiView specialist hemispherical photography software. We recommend a combination of smartphone photography with fisheye attachment and analysis with ImageJ for identifying changes in the timing of canopy closure (but not for estimating absolute canopy closure). We discuss how large-scale citizen science using this approach could generate meaningful and comparative data on the timings of canopy closure in different forests, year-to-year. 


\section{Introduction}

Climate change is affecting forest ecosystems around the globe, with changes in tree phenology widely documented for temperate forests (Richardson et al., 2013; Roberts et al., 2015; Vitasse et al., 2011). Growing season extensions have been observed for many European tree species, most notably due to canopies coming into leaf earlier (Menzel and Fabian, 1999; Menzel et al., 2006; Thompson and Clark, 2008). The phenology of dominant canopy trees exerts strong influence on the understorey environment, as canopy openness is highly related to available photosynthetically active radiation (PAR) (Brusa and Bunker, 2014; Gonsamo et al., 2013; Promis et al., 2012), influencing microclimate, soil respiration (Giasson et al., 2013; Yuste et al., 2004) and understorey plant dynamics (Van Couwenberghe et al., 2011). Therefore, earlier canopy closure and later senescence is likely to have wide-ranging impacts on the phenology and life processes of understorey plants and wider forest biodiversity. Studies have indicated threats to spring ephemeral herbs that utilise the period before canopy closure for completing their life cycle (Kim et al., 2015). Many tree saplings depend on spring sunlight prior to canopy closure for their growth and survival (Augspurger, 2008). Understorey species that are shade tolerant or those with greater phenological plasticity are likely to gain competitive advantage (De Frenne et al., 2011), and invasive species could become more prevalent (Engelhardt and Anderson, 2011; Willis et al., 2010). As canopy openness is a key determinant of ecological processes in the understorey, effective methods for monitoring intra and inter-annual changes in the timing of canopy closure/openness would be very useful, especially if they allowed data to be collected across a variety of spatial scales, and with plenty of replication.

Canopy phenology has been extensively studied in recent years. Satellite remote sensing has enabled data collection of forest leaf phenology at large spatial scales (Boyd et al., 2011; Wang et al., 2016; White et al., 2009; Wu and Liu, 2013; Zhang et al., 2005). These methods focus on deriving estimates of canopy green-up dates from Normalised Difference Vegetation Index (NDVI) or Enhanced Vegetation Index (EVI) data, for the purpose of tracking photosynthetic activity to assess forest productivity, gas exchange and phenological feedbacks to the climate system (Richardson et al., 2013). While remote sensing data is useful for identifying large-scale phenological trends, the coarse resolution means that local variations between forest stands are often masked (Fisher et al., 2006; White et al., 2014). Furthermore, loss of temporal resolution due to 
atmospheric conditions (Cleland et al., 2007; White et al., 2014), and difficulties separating greening of the understorey from canopy greening (Hamunyela et al., 2013), can compromise the use of this data for identifying shifts in canopy closure timing.

A range of ground-based methods have been used to assess canopy structure and understorey light environments at the forest-level. Direct measures of understorey light are highly affected by sky conditions and accurate determination requires continuous measurement over several days (Engelbrecht and Herz, 2001; Gendron et al., 1998). This makes direct measurements inappropriate for phenology studies where the objective is to assess variation through time. As an alternative, hemispherical photography and Plant Canopy Analysers (PCAs) such as the LAI-2200, are commonly used to assess structural attributes of forest canopies (Frazer et al., 1997; Gonsamo et al., 2013; Hale and Edwards, 2002; Rich, 1990). Both instruments incorporate an extreme wide angle view to measure gap fraction - defined as the proportion of unobstructed sky in a given region of the projected image plane (Frazer et al., 1997) - at multiple zenith angles. For estimating understorey light levels, particularly during spring, wide viewing angles are an advantage as sunlight largely penetrates the canopy below the zenith. Using gap fraction measurements, Leaf Area Index (LAI) and canopy openness can be determined.

LAl is the most widely used metric of canopy structure (Jonckheere et al., 2005; Weiss et al., 2004), though it is also one of the most difficult to characterise accurately (Bréda, 2003). LAI is defined as one half the total green leaf area per unit ground surface area (Chen and Black, 1992). Hemispherical photography and PCAs assess the whole canopy as viewed from a single point, using gap fraction inversion principles and radiative transfer theory respectively (Chen et al., 1997; Macfarlane et al., 2007; Woodgate et al., 2015). As such, LAI derived from optical methods actually characterises 'Plant Area Index' (as trunks and branches are included as well as leaves), and is highly related to understorey light levels (Bréda, 2003; Jonckheere et al., 2004). However, both methods are costly, particularly PCAs, which in addition to high instrument costs, require simultaneous reference light readings outside the canopy. This is problematic in forests, as a wireless set up or remote data loggers are needed, adding additional resource implications and making the method impractical for large-scale use (Bréda, 2003). Furthermore, both methods for estimating LAl assume that canopy elements are randomly distributed. In reality, a degree of 'clumping' occurs both within and between plant canopies (Bréda, 2003; Chen et al., 1997; Ryu et al., 2010; Weiss et al., 2004). The degree of clumping 
108

109

varies depending on forest type and structure, and also shows strong seasonal variation according to the phenological stage (Ryu et al., 2010). Therefore accurate LAl estimation requires determination of a clumping index for a given canopy at a given time of year, and specialist equipment and/or software is required (Chianucci et al., 2015; Ryu et al., 2010).

Digital Cover Photography (DCP) using ordinary digital cameras can also be used to estimate LAl following the method proposed by Macfarlane et al. (2007). This method has a number of advantages as specialist equipment and software are not required, though a number of steps are involved in analysis to calculate effects of foliage clumping (Chianucci et al., 2014; Macfarlane et al., 2007). DCP has been successfully used to track canopy development in phenological studies concerned with photosynthesis and gas exchange (Ryu et al., 2012). However, the restricted viewing angle of DCP cover photography is less appropriate for tracking the progress of canopy closure, where the objective is to assess change in the relative timing of shading in the understorey. Although LAI is highly related to understorey light (particularly where it is based on gap fraction at multiple zenith angles) it is primarily used to quantify ecosphysiological attributes of forest canopies (photosynthetic and transpiration rates) to study climate-biosphere interactions (Bréda, 2003; Chen et al., 1997; Jonckheere et al., 2004; Macfarlane et al., 2007; Woodgate et al., 2015). Where the aim is to track changes in relative canopy closure to determine temporal variability in understorey light, canopy openness is a more appropriate and straightforward metric to use (Brusa and Bunker, 2014).

Canopy openness is the proportion of the entire sky hemisphere that is unobstructed by vegetation when viewed from a single point (Jennings et al., 1999), and is highly correlated with understorey light (Brusa and Bunker, 2014; Gonsamo et al., 2013; Pellikka, 2001; Promis et al., 2012; Roxburgh and Kelly, 1995; Whitmore et al., 1993). Hemispherical photography has been widely used to assess canopy openness, representing the sum of all gap fraction values, weighted according to zenith angle, and multiplied by 100 to give a percent visible sky value (Frazer et al., 1997). The advent of digital cameras and their increasing availability has made hemispherical photography more widely available for forest science (Brusa and Bunker, 2014; Frazer et al., 2001; Hale and Edwards, 2002; Inoue et al., 2004). However, cost and resource implications still preclude many forest managers from using it as a monitoring tool. While hemispherical photography does not require reference light readings to be made, images must be taken under specific weather conditions - on dry, still days, without 
141 direct sunlight, normally early or late in the day, or on a day with uniform overcast skies 142 (Rich, 1990). This places considerable constraint on when data can be collected. Once 143 images have been obtained, analysis can be time-consuming and expensive. Though 144 free specialist software programmes now exist that provide comparable results to 145 professional software (Promis et al., 2011), expertise is still required. Overall, the 146 technique is prohibitively expensive, in terms of cost and time, for phenology studies 147 that require high levels of replication.

148 A variety of cost-effective, rapid assessment alternatives to hemispherical photography 149 have been used to assess canopy openness, including photography without a fisheye 150 lens (Pellikka, 2001), the canopy scope (Brown et al., 2000), and simple visual estimations (Jennings et al., 1999). These methods differ in their view zenith angle; therefore canopy openness in this context is defined as the proportion of unobstructed sky within the total area viewed. While these methods are used to characterise coarselevel variation in canopy openness, their ability to detect fine-scale changes in canopies through time needs to be assessed. Another option has emerged in the last few years with the rise of smartphones that have high resolution cameras. Inexpensive fisheye lens attachments for smartphones have recently become available for less than US\$10. Smartphone photography, if reliable, could provide an efficient means of collecting large quantities of data on the timing of canopy closure using citizen science.

The use of citizen science has proven highly successful in other areas of phenological research, including observational studies of plant bud-burst and leaf-out timing (Collinson and Sparks, 2008; Jeong et al., 2013; Mayer, 2010). The widespread and increasing ownership of smartphones means that many people now carry sophisticated cameras, making them ideal citizen science tools. However, a considerable range of makes and models exist. These vary in their camera specifications (e.g. resolution, focussing capability and angle of view), which could affect canopy openness estimations (Frazer et al., 2001; Inoue et al., 2004; Jennings et al., 1999). Therefore, for this method to be practical for large-scale use, different makes and models of smartphone need to give comparable estimations.

170 In this study, we compared canopy openness values (\% visible sky) from hemispherical 171 photography, with estimates derived from visual estimation techniques and from 172 smartphone photography, with and without the use of a fisheye lens attachment. Data 173 were collected in winter, spring, summer and autumn, at fixed points across four 
174 broadleaved woodlands in south-west England, to assess the extent that surrogate

175 methods can estimate variation in canopy openness. We then tested a basic means of

176 analysing hemispherical photos and smartphone fisheye photos to derive canopy

177 openness using non-specialist image analysis software. We did this by comparing

178 simple canopy openness values (\% visible sky) derived from the free image-analysis

179 software, with weighted canopy openness values (\% visible sky weighted as a function

180 of gap fraction zenith angle) from professional specialist software. Recognising that

181 different makes of smartphone camera might perform differently, we also compared

182 three popular smartphone cameras in a separate trial. The different phone cameras

183 were tested in broadleaved woodland under three levels of canopy density, and with

184 multiple camera operators, to test reproducibility under different canopy conditions and

185 with different users.

186 Our overall objectives were: a) to identify whether any of the proposed surrogate

187 methods provide reliable estimates of variation in canopy openness; b) to identify

188 whether non-specialist image analysis software can produce comparable estimates to

189 specialist software; c) to test whether different smartphone camera models and different

190 camera users yield similar canopy openness estimations. It is important to note that this

191 study was not concerned with identifying methods to closely represent absolute values,

192 since it has already been established that methods incorporating different view angles

193 tend to give different absolute estimates of canopy openness (Bunnell and Vales, 1990;

194 Cook et al., 1995). Our focus was to identify whether any of the alternative methods

195 could reliably identify relative differences in canopy openness to monitor canopy closure 196 timings, and promote data collection through large-scale citizen science.

\section{2. Methods}

\section{2.1. Comparison of methods against hemispherical photography}

199 Trials took place in 2014 at four woodlands in Devon, England. The suite of sites was 200 purposely chosen to represent a range of canopy/understorey light conditions, with 201 varying aspect, composition and structure (Table 1). Six fixed sample points or 'stations' 202 were randomly selected in each of the four woodlands. At each station, canopy 203 openness was estimated by a variety of methods in each season (related to leaf 204 phenology): winter (no canopy), spring (around 50\% leaf-out), summer (full canopy) and 
205 autumn (around 50\% leaf-drop). All estimates were made concurrently for a woodland 206 within each season, and the four woodlands all estimated within a week of each other.

207 2.1.1. Hemispherical photography

208 Hemispherical photographs were taken in colour using a Nikon Coolpix 9903.34 MP 209 camera with Nikon Fisheye Converter FC-E8 lens (Nikon Corporation, Tokyo, Japan). 210 The circular fisheye lens provides a $180^{\circ}$ field of view in all directions. Images were 211 taken using the basic quality setting and stored in VGA-size, as canopy openness 212 estimates are not affected by resolution or size settings with this camera model (Inoue 213 et al., 2004).

214 Photos were taken without rain or direct sunlight entering the lens (Rich, 1989). The camera was mounted on a tripod at $1.2 \mathrm{~m}$ above ground, and levelled using a circular bubble level. Pictures were taken using the camera timer function to reduce movement 217 during image capture (Rich, 1989). Aperture and shutter settings were set to automatic, 218 and to minimise error from over-exposure (Brusa and Bunker, 2014; Hale and Edwards, 219 2002), exposure was checked using the histogram function in the camera playback 220 facility, following the method outlined by Beckschafer et al. (2013). Where over221 exposure was apparent, exposure settings were manually lowered to $-2.0 \mathrm{EV}$, the 222 minimum limit on this camera.

223 Images were analysed in HemiView Canopy Analysis Software v.2.1 (Delta-T Devices, 224 Cambridge, UK). The Coolpix 900 lens settings in HemiView were selected to correct 225 for lens distortion (Hale and Edwards, 2002). Various options exist for classifying a 226 photograph into "sky" and "not sky" (binarization), using image analysis software 227 (Glatthorn and Beckschafer, 2014; Zhao and He, 2016). In HemiView, it is only possible 228 to use manual thresholding of black and white pixels, so we followed this method, which has been widely used in other studies (Bertin et al., 2011; Capdevielle-Vargas et al., 2015; Hale and Edwards, 2002; Machado and Reich, 1999; Zhang et al., 2005). Each

231 photograph was individually processed to obtain the best contrast between vegetation 232 and the background sky, by visual comparison with the original photograph (Rich, 233 1990). A decision was made, based on visual assessment during threshold setting, 234 whether each photo should be included in the analysis. If it was not possible to gain a 235 good contrast between sky and vegetation across the whole image, that photo was excluded. Canopy openness - in HemiView, "\% visible sky" — was then derived for each 
237 image by the software. In HemiView this value represents a weighted canopy openness score based on gap fraction zenith angles (Rich et al., 1999).

239 Following analysis in HemiView, photos were also analysed using ImageJ (Rueden,

240 2016). Photos were converted to 8-bit binary black ("not sky") and white ("sky") images

241 in ImageJ. Following the same procedure as we used for photos in HemiView, the

242 manual thresholding function in ImageJ was used to individually process each image

243 and obtain the best contrast between vegetation and background sky. This was done

244 with reference to the original photograph (Rich, 1990). Hemispherical photos consist of

245 a circular image inside a rectangular frame. As ImageJ is not designed specifically for

246 such images, it cannot automatically exclude the framing pixels as is possible in

247 HemiView. Therefore to calculate canopy openness (the proportion of pixels classified

248 as sky) excluding the frame, we first calculated the number of pixels in a reference

249 image containing only open sky. We then used the 'batch measure function' to calculate

250 white (sky) pixels for all images, and calculated the canopy openness as a proportion of

251 the circular hemispherical image, excluding the framing pixels.

252 2.1.2. Smartphone photography with fisheye lens

253 Photos were taken using a Sony Xperia L smartphone camera (Android Version 5.0) 254 with magnetic fisheye lens attachment (Skimn FE-12 $180^{\circ}$ fisheye lens). Images were taken at 5 MP using a 16:9 aspect ratio - the camera's default settings. Using these settings, the fisheye lens gave a $125^{\circ} \times 75^{\circ}$ field of view. The smartphone was held level, with the wider view orientated east-to-west when taking photos of the canopy, to ensure comparable images were obtained for each season. Photographs were taken in

259 manual mode, with exposure lowered to -2.0 EV, the minimum limit on the camera.

$\$ 60$ Images were stored as high quality JPEGs, between 2-3_MB in size.

261 Smartphone fisheye photos were analysed in HemiView and ImageJ and visible sky values were calculated, following the same procedures outlined for hemispherical photo analysis. Lens equation coefficients relating zenith angles and radial distance were calculated from a calibration curve constructed from measurements taken from

265 reference photographs. The resulting lens correction function $(y=1.2213 x$ -

$\left.2661.396 x^{2}+1.0855 x^{3}-0.2761 x^{4}\right)$ was used by HemiView to adjust the calculations to correct 267 for lens distortion.

268 2.1.3. Smartphone photography without a fisheye lens 
269 Smartphone photos were also taken of the canopy without the fisheye lens attachment,

270 giving a $70^{\circ} \times 40^{\circ}$ field of view. Photos were taken of the canopy directly overhead (with

271 the wider view orientated east-west), and of the canopy facing in three different

272 bearings from the station - at $60^{\circ}, 180^{\circ}$ and $300^{\circ}$ (with the camera positioned in a

273 landscape orientation at a at $45^{\circ}$ angle from the horizontal). All photos were taken

274 using the same settings as the photos with fisheye lens attachment, and exposure

275 settings were manually adjusted as previously described. Photographs were then

276 analysed using ImageJ, following the same procedure for binarization, to derive a

277 canopy openness estimation based on \% visible sky. Two sets of canopy openness

278 estimates were derived from these photos: one based solely on the overhead canopy

279 photo, and one calculated as an average from all four photographs to incorporate a

280 wider area of view.

\section{2.1.4. Non-photographic methods}

282 Canopy openness was estimated visually on a simple percentage scale. Two sets of 283 canopy openness estimates were derived, one based solely on an overhead estimation, 284 and another based on an average of four estimations: one directly overhead, and at 285 three different bearings from the station $\left(60^{\circ}, 180^{\circ}\right.$ and $\left.300^{\circ}\right)$ at a $45^{\circ}$ angle from the 286 horizontal.

287 Brown et al. (2000) proposed a canopy scope to aid in the visual estimation of canopy 288 openness. The scope consists of a simple Perspex sheet with a grid of twenty-five dots, 289 spaced $3 \mathrm{~cm}$ apart in a 5x5 array. A $20 \mathrm{~cm}$ length of string is attached to the corner, and 290 ensures the scope is held at a constant distance from the eyes when making 291 estimations. Canopy openness was estimated by focussing the scope on the largest 292 canopy gap visible from the station, and counting the number of dots coinciding with 293 sky. This number was then multiplied by four to obtain a percentage estimate. Brown et 294 al. (2000) found a close correlation between largest gap canopy openness and total 295 canopy openness, but acknowledged that for woodlands with several similar sized 296 canopy gaps, the largest gap estimate may not give an accurate representation. Two 297 alternative estimates were made: one by pointing the canopy scope at the canopy 298 directly overhead; and another by taking the mean of four canopy scope estimates 299 (using the overhead estimate and estimates made from viewing the canopy at bearings 300 of $60^{\circ}, 180^{\circ}$ and $300^{\circ}$ from north, at an approximately $45^{\circ}$ angle from the horizontal). 
2.1.5. Statistical analysis

302 We used linear regression to compare canopy openness derived from hemispherical photographs in HemiView, against each surrogate method. We first compared data from

304 all seasons and sites together to assess which methods were able to estimate broad changes in canopy openness. We then compared methods on a season-by-season basis across the four sites, to understand whether methods were capable of estimating

307 finer-scale variation in canopy openness. We also conducted method comparisons on a 308 site-by-site basis using data from all four seasons, to assess whether methods 309 performed well across the different woodlands.

310 For methods that performed consistently well across the comparisons, Analysis of

311 Covariance (ANCOVA) was used to test whether the methods estimated canopy 312 openness in similar ways under different conditions, with seasons and sites as 313 covariates. A Tukey-Kramer test was used to explore differences that were found 314 between seasons or sites. All statistical analyses were carried out in R 3.3 (R Core 315 Team, 2016).

\section{$316 \quad$ 2.2. Comparison of smartphone models and operators}

317 2.2.1. Field imagery

318 A second trial comparing smartphone models and phone users took place in mixed deciduous woodland at Mount Edgcumbe Estate, Cornwall (approximately $50^{\circ} 35^{\prime} \mathrm{N}$ and $\left.4^{\circ} 16^{\prime} \mathrm{W}\right)$, during summer when trees were in full leaf. Three sampling locations or 'stations' were selected at the site, using visual assessment, to represent a 'closed', 'intermediate' and 'open' overhead canopy. We tested two popular Smartphone cameras - the iPhone 5 and Samsung Galaxy S4 - against the Sony Xperia used in the previous trials, to assess the comparability of canopy openness estimates. Photos taken with the iPhone 5 had a resolution of $8 \mathrm{MP}$ and an aspect ratio of $16: 9$, providing a $61^{\circ} \mathrm{x}$ $48^{\circ}$ field of view. Photos taken with the Samsung Galaxy S4 had a resolution of 9.6 MP and aspect ratio of $16: 9$, providing a $57^{\circ} \times 34^{\circ}$ field of view. Photos were stored as high quality JPEGS, between 2-3 MB in size.

329 Twenty-two volunteers consecutively took an overhead photograph of the canopy with 330 each camera, at each of the three stations. All photos were taken within a half-hour 331 period. Volunteers were instructed to hold the phone at an estimated level position and 332 take a photo of the canopy above, but were not told to orientate the phone in a 
particular direction, as we were interested to see the extent that individual user operation affected consistency in the results. Photos were analysed in Image J following the procedure outlined above.

2.2.2. Statistical analysis

The Aligned Rank Transform (ART) procedure in the R package ARTool (Kay and Wobbrock, 2016), followed by separate ANOVA using R 3.3 (R Core Team, 2016), was used to assess the effects of phone user, phone model and canopy treatment on canopy openness values. The ART procedure is an appropriate way to analyse datasets which are not normally distributed, and is described in more detail by Wobbrock et al. (2011). We performed post hoc contrasts using estimated marginal means with the emmeans package (Lenth, 2017).

\section{3. Results}

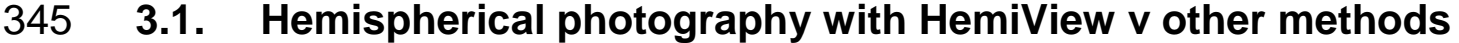

346 All hemispherical photos taken were suitably exposed in relation to sky conditions, for inclusion in the analysis, while four smartphone fisheye photos and six smartphone photos without the fisheye lens attachment were eliminated due to overexposure, out of 96 photos in each case.

Analysis of hemispherical photography with ImageJ produced reliable estimates of canopy openness values derived from analysis with HemiView (Table 2, Figs 1A and 1D). With photos from spring, summer and autumn combined into a single ANCOVA analysis, the slope of the relationship was no different for all three seasons (Fig. 1D ANCOVA $\left.F_{2,66}=2.55, p=0.09\right)$. However, the intercepts of the relationships were significantly different (Fig. 1D ANCOVA $F_{2,68}=8.09, p<0.001$ ), with summer values estimated relatively lower than those of spring and autumn (Tukey-Kramer Test, summer $v$ spring $p=0.004$, summer $v$ autumn $p<0.001$, spring $v$ autumn $p=0.864$ ). None of the other methods closely estimated absolute canopy openness values derived from hemispherical photography, but all smartphone photographic methods reliably

360 estimated relative differences in canopy openness across all seasons for all sites (Table 3612 2, Figs 1B and 1C). The slopes of these relationships, which were all $>1$, indicate that smartphone fisheye photography results in higher estimates of canopy openness than hemispherical photography, and that the estimates differ more at higher values of 
canopy openness. During winter, when there were very high levels of canopy openness ( mean $=37 \%$, sd $=5 \%$ ), smartphone fisheye photos did not correspond reliably to hemispherical photography (Table 2). This was also true for all other methods tested, and since winter is not a season where canopy change is expected and therefore not relevant to our aims, winter data were excluded from the rest of the analyses. Nonphotographic methods (canopy scope and simple visual estimations) were much poorer estimators of change in canopy openness across all seasons and sites (Table 2). Smartphone with fisheye lens estimates taken in different seasons had similar slope relationships (Fig. 1E ANCOVA $F_{2,66}=0.31, p=0.73$; Fig.1F $F_{2,66}=0.64, p=0.53$ ), but they varied in intercept (Fig 1E, ANCOVA $F_{2,64}=33.56, p<0.001$; Fig. $1 \mathrm{~F} F_{2,64}=48.73$, $p<0.001)$. For smartphone photographs analysed with HemiView canopy analysis software, spring and autumn intercepts were not significantly different (Tukey-Kramer $p$ $=0.796)$, but both were significantly different from summer $(p<0.001$ in each case). The same photographs analysed with ImageJ had different intercepts for each of the three seasons (spring $v$ autumn $p=0.020$, spring $v$ summer $p<0.001$, summer $v$ autumn $p<0.001)$.

Since smartphone fisheye photography and ImageJ analysis reliably estimated variation in canopy openness, we tested whether the methods performed consistently between different sites (Fig. 2). Hemispherical imagery analysed with ImageJ showed similar slope relationships across all sites (Fig. $2 A$; ANCOVA $F_{3,64}=1.17, p=0.33$ ), but significant differences in intercept (ANCOVA $F_{3,67}=4.75, p=0.005$ ). The intercept of Hardwick was different from Hunshaw and Whitleigh (Tukey-Kramer Test, $p=0.018$ and $p=0.007)$, though all other intercepts were not different $(p=0.288$ to 1.000$)$.

Smartphone with fisheye photography, whether analysed with HemiView or ImageJ, resulted in different slope relationships for Hardwick compared to the other sites (Fig. 2B, ANCOVA $F_{3,60}=4.10, p=0.010$; Fig. $\left.2 \mathrm{C}, F_{3,60}=7.07, p<0.001\right)$. As canopy openness increased, the estimates for Hardwick differed less from the hemispherical standard than the other sites. The intercepts of the other sites did not differ (Fig. 2B, ANCOVA $F_{2,46}=0.91, p=0.41$; Fig. $\left.2 C, F_{2,46}=0.54, p=0.59\right)$.

\subsection{Comparison of smartphone models and operators}

394 The three canopy treatments (closed, intermediate and open) were clearly different from each other in terms of canopy openness, but it did not matter which phone model or 
user took the photos (Fig. 3; Aligned Rank Transform + ANOVA, $p_{\text {canopy }}<0.0001$, $p_{\text {user }}$

$397=1.00$ and pmodel $=0.50$ ). However, variability in estimation of canopy openness

398 increased markedly as canopy openness increased. For the closed canopy, standard

399 deviations of the estimates ranged from $0.79-1.46 \%$ canopy openness, but were much

400 greater for the open canopy (7.42-12.43\%).

\section{4. Discussion}

402 Our results showed that smartphone photographic methods estimated variation in 403 canopy closure effectively, but rapid visual estimation methods did not. Basic visual 404 estimations of canopies are known to lack consistency, varying considerably due to 405 weather conditions (Jennings et al., 1999) and observer biases (Vales and Bunnell, 406 1988). The canopy scope is more a quantitative visual estimation method, allowing for 407 greater consistency and has been shown to have low between-observer bias (Brown et 408 al., 2000), so is potentially more suitable for citizen science. However, while the canopy 409 scope can distinguish quite different degrees of canopy openness (Brown et al., 2000), 410 it lacked the fine resolution needed to distinguish between similar canopies, and 411 therefore is less suitable for monitoring changes through time.

412 Smartphone photographic methods have now become a cost effective and practical 413 alternative to visual estimation. Simple photographs using a smartphone camera without 414 a lens attachment were sufficient for assessing the degree of variation in canopies 415 across a whole season, but did not pick up fine-scale variations (i.e. between similar 416 canopies within a season) compared with hemispherical photography. This is 417 unsurprising, as their narrow angle of view means they are essentially providing an 418 estimate of canopy cover directly overhead, as opposed to canopy closure across a 419 range of zenith angles (Chianucci et al., 2014; Jennings et al., 1999). With the addition 420 of an inexpensive fisheye lens attachment, smartphone photographs were able to pick 421 up finer variations in canopy openness in spring, summer and autumn, which would be 422 important for monitoring seasonal dynamics.

423 As anticipated, smartphone fisheye photography gave higher canopy openness 424 estimations than hemispherical photography, due to its narrower field of view. With 425 hemispherical photography, an image taken within a forest will typically include a ring of 426 tree trunks and shrubs around the periphery, with low gap fractions in the outer portions 427 of the image (at larger zenith angles) (Chen et al., 1997). Although incorporating a 
428 greater field of view than non-fisheye photos, smartphone fisheye photos still omit the

429 largest zenith angles containing most of the lower trunks and shrub layer. In its field of

430 view, the gaps in a canopy contribute more to the overall image. Similarly, twigs and

431 foliage have higher prominence in images. As smartphone fisheye photography misses

432 gaps at larger zenith angles, it would not be a suitable method for detailed studies of

433 canopy structure or plant growth. However, the method is suitable for monitoring timing

434 of canopy closure, and its narrower field of view could actually make it a superior

435 method for identifying leafing activity early in spring.

436 We found canopy structure affected the relationship between hemispherical

437 photography and smartphone photography, meaning that canopy openness values must

438 be converted to proportions of total canopy closure to be correctly interpreted. Where

439 the overhead canopy was uniformly closed, the difference between canopy openness

440 estimations from smartphone fisheye photos and hemispherical photos was lower -

441 both sets of images show a closed canopy with few gaps. In more open situations, the

442 difference between the two sets of estimations was greater. Similarly where stand

443 density was higher and the height of the tree canopy was lower (e.g. at Hardwick Wood,

444 Table 1), the difference between canopy openness values from the two methods was

445 smaller. Canopy height is known to effect openness estimations when the field of view

446 is reduced (Jennings et al., 1999; Pellikka, 2001).

447 Due to the influence of canopy structure on canopy openness values, we propose this

448 method is appropriate for monitoring relative change in canopies through time. In order

449 to compare the timing and rate of canopy closure across different forest locations we

450 can standardize along a proportional scale of canopy closure, where $0 \%$ represents the

451 winter canopy value prior to budburst, and 100\% represents the summer canopy value

452 once the canopy is fully in leaf. We note that canopies are dynamic, and small-scale

453 fluctuations occur through summer. Therefore the summer canopy value would be

454 determined from the point where the canopy reaches 'adjustment stability' (Margalef,

455 1969), after which only small changes of less than $2 \%$ canopy closure are observed.

456 The progress of canopy closure can then be plotted through time from $0-100 \%$, and a

457 logistic growth model can be fitted to characterise the phenological pattern (Richardson

458 et al., 2006; Zhang et al., 2003). An example using smartphone fish-eye photography is

459 provided in Supplementary Material. 
460 In terms of photo analysis, we found that ImageJ is a reasonable alternative to 461 professional specialist software such as HemiView, for deriving relative canopy

462 openness values. It is clear that ImageJ overestimates values from HemiView to some 463 degree, so again, this method would not be suitable for studies where absolute values 464 were needed. The distortion of a hemispherical or fisheye lens causes the central part 465 of the image, towards the zenith, to appear larger than peripheral elements towards the 466 horizon (Herbert, 1987). Canopy openness derived from HemiView is based on a 467 weighted gap fraction that takes into account the zenith angle of canopy gaps, and 468 corrects for a given lens distortion (Promis et al., 2011). In contrast, canopy openness 469 derived from ImageJ is simply the percentage visible sky across the image. However, 470 values from ImageJ still consistently and reliably estimated relative differences in 471 canopy openness in our study.

472 ImageJ has the benefits of being free, open access and relatively straightforward to use. 473 It is not necessary to provide specifications of the fisheye lens to use it. Image 474 binarization is still required, which can be time consuming. The manual thresholding 475 technique used in this study would not be suitable for analysing large quantities of 476 citizen science data. Many citizen science projects have successfully utilised internet 477 crowd-sourcing applications (Kosmala et al., 2016) to involve the public in processing 478 and classifying large numbers of images, so a similar approach could be used to 479 binarize canopy photos, with multiple people classifying pixels for the same image to 480 reduce error (Inoue et al., 2011). However, new methods for automatic thresholding of 481 photos would improve efficiency (Brusa and Bunker, 2014; Glatthorn and Beckschafer, 482 2014; Inoue et al., 2004), and auto-thresholding plug-ins for ImageJ (Glatthorn and 483 Beckschafer, 2014) could provide a viable option.

484 In terms of practicalities, smartphone fisheye photography is suitable for widespread 485 use as part of citizen science projects, and if managed properly is a game-changer in 486 terms of data quantity. The good agreement between smartphone models and users 487 suggests the method can be reliably applied by citizen scientists. The three phone 488 models tested varied in resolution and field of view, but still produced comparable 489 results. While some variation was evident between photos taken with the same phone, 490 under the same canopy conditions, there was no overall effect of phone user on canopy 491 openness values. Variation between photos taken with the same phone was greatest at 492 higher levels of canopy openness. This is not surprising, as under the dense canopy, 

gaps were small and uniformly distributed, whereas the open canopy comprised a very large central gap bordered by canopy. Small variation in camera positioning could therefore result in compositional differences between photographs. This could lead to significant differences in estimates, as has been observed with other methods for estimating canopy openness (Jennings et al. 1999). Therefore, we recommend that for best results camera position is standardised by installation of fixed camera mounts (University of New Hampshire, 2017) for citizen scientists to place their smartphones on in order to take repeat photographs of particular parts of the canopy.

The quality of photos obtained from smartphone fisheye photography is sufficient to obtain reliable data. The high resolution available with smartphone cameras is a clear advantage. Resolution is known to be an important factor influencing the quality of canopy openness measures from hemispherical photography (Brusa and Bunker, 2014; Woodgate et al., 2015), and in this study the smartphone camera resolution was superior to that of the hemispherical camera (with nearly $2,000,000$ more pixels). It has also been noted that higher resolution images are less vulnerable to thresholding errors during image processing and analysis (Macfarlane et al., 2007). Some blurring was evident towards the perimeter of the smartphone fisheye photos, but this is also apparent with hemispherical photos (Frazer et al., 2001). Blurring from motion caused by holding the camera to capture images could also influence image quality (Woodgate et al., 2015). The use of fixed mounts for phone cameras would help alleviate this problem, as well as utilising the camera's timer function or earphone controls to remotely operate the camera shutter.

As with hemispherical photography, there are several logistical issues associated with the use of smartphone photography, relating to sky conditions and image exposure. The effects of over-exposure and the importance of taking photos under uniform sky conditions has been emphasised in many studies (Beckschafer et al., 2013; Brusa and Bunker, 2014; Rich, 1990; Woodgate et al., 2015; Zhang et al., 2005). In this study, a small proportion of smartphone photos had to be excluded due to over-exposure. While smartphone photographs were taken at -2.0 EV, the lowest exposure setting available, Beckschafer et al. (2013) showed that over-exposure can still occur at -2.0 EV under bright skies. This can also be a problem with hemispherical photography, as the Nikon Coolpix 990 had the same limits for exposure compensation. The histogram function allows a definitive check as to whether photos are over-exposed, and more advanced 
526 cameras allow for lowering below -2.0 EV (Beckschafer et al., 2013). We emphasise

527 again that the smartphone fish-eye photography method would not be suitable for

528 detailed studies of canopy structure or growth where small differences between sites

529 must be detected, and therefore consistent exposure is paramount (Leblanc, 2005).

530 However, to track the progress of canopy closure through time and compare trends in

531 the timing of this phenological event over large spatial scales, a small degree of noise in

532 the data is acceptable. The example in Supplementary Material demonstrates that the

533 phenological process of canopy closure can be clearly modelled using this method.

534 While the limits of exposure settings on smartphone cameras may mean some photos

535 have to be discarded, the greater number of images obtained by utilising a citizen

536 science approach should increase the number of suitable images that can be included

537 in a study. Where possible citizen scientists should be encouraged to take photos early

538 or late in the day, which is when sky conditions are generally most appropriate, and

$\$ 39$ coincides with times when people are likely to be available to collect imagery.

\section{5. Conclusions}

541 Smartphone fisheye photography, with relatively simple image analysis, offers a

542 practical method for comparing changes in the timing of canopy closure across different

543 forests year on year, and may even be more suited to this task than hemispherical

544 photography. Using this approach, trends in proportional changes in canopy closure

545 could be identified across different spatial and temporal scales using citizen science.

546 Further research is required to assess the temporal resolution of image capture needed

547 to represent canopy changes adequately.

\section{6. Acknowledgements}

549 We would like to thank Jacqueline and Adrian Wolfe, Clinton Devon Estates, and the

550 Woodland Trust for granting permission to study their woodlands. Nicola Steer helped

551 with the modelling of our datasets in Supplementary Material. Conservation Biology

552 students at University of Plymouth participated in the smartphone photo trials: Eleanor

553 Arthur, Mike Cox, Megan Dalton, Emily Daniel, Jacob Dansie, John Davey, Rebecca

554 Dickson, Simon Harrington, Ziad Ibbini, Alex King, Niall Legg, Jordan Maskell, Ella

555 Mutch, Guy Palmer, Scott Patterson, Julian Prow, James Robertshaw, Jessica

556 Robertson, Emma Shadbolt, Rhys Smith, Jack Whittington and Jamie Witherford. This 
research did not receive a grant from funding agencies in the public, commercial, or notfor-profit sectors.

\section{References}

560

Augspurger, C.K., 2008. Early spring leaf out enhances growth and survival of saplings in a temperate deciduous forest. Oecologia, 156(2): 281-286.

Beckschafer, P., Seidel, D., Kleinn, C. and Xu, J.C., 2013. On the exposure of hemispherical photographs in forests. J. Biogeosci. For., 6(4): 228-237.

Bertin, S., Palmroth, S., Kim, H.S., Perks, M.P., Mencuccini, M. and Oren, R., 2011. Modelling understorey light for seedling regeneration in continuous cover forestry canopies. Forestry, 84(4): 397-409.

Boyd, D.S., Almond, S., Dash, J., Curran, P.J. and Hill, R.A., 2011. Phenology of vegetation in Southern England from Envisat MERIS terrestrial chlorophyll index (MTCI) data. Int. J. Remote Sens., 32(23): 8421-8447.

Bréda, N.J.J., 2003. Ground-based measurements of leaf area index: a review of methods, instruments and current controversies. J. Exp. Bot., 54(392): 2403-2417.

Brown, N., Jennings, S., Wheeler, P. and Nabe-Nielsen, J., 2000. An improved method for the rapid assessment of forest understorey light environments. J. Appl. Ecol., 37(6): 10441053.

Brusa, A. and Bunker, D.E., 2014. Increasing the precision of canopy closure estimates from hemispherical photography: Blue channel analysis and under-exposure. Agric. For. Meteorol., 195-196: 102-107.

Bunnell, F.L. and Vales, D.J., 1990. Comparison of methods for estimating forest overstory cover: differences among techniques. Can. J. Forest Res., 20(1): 101-107.

Capdevielle-Vargas, R., Estrella, N. and Menzel, A., 2015. Multiple-year assessment of phenological plasticity within a beech (Fagus sylvatica L.) stand in southern Germany. Agric. For. Meteorol., 211-212: 13-22.

Chen, J.M. and Black, T.A., 1992. Defining leaf-area index for non-flat leaves. Plant Cell Environ., 15(4): 421-429.

Chen, J.M., Rich, P.M., Gower, S.T., Norman, J.M. and Plummer, S., 1997. Leaf area index of boreal forests: Theory, techniques, and measurements. J. Geophys. Res. Atmos., 102(D24): 29429-29443.

Chianucci, F., Chiavetta, U. and Cutini, A., 2014. The estimation of canopy attributes from digital cover photography by two different image analysis methods. iForest Biogeosci. For., 7: 255-259.

Chianucci, F., Macfarlane, C., Pisek, J., Cutini, A. and Casa, R., 2015. Estimation of foliage clumping from the LAI-2000 Plant Canopy Analyzer: effect of view caps. Trees-Struct. Funct., 29(2): 355-366.

Cleland, E.E., Chuine, I., Menzel, A., Mooney, H.A. and Schwartz, M.D., 2007. Shifting plant phenology in response to global change. Trends Ecol. Evol., 22(7): 357-365. 
Collinson, N. and Sparks, T., 2008. Phenology-Nature's Calendar: an overview of results from the UK Phenology Network. Arboric. J., 30(4): 271-278.

Cook, J.G., Stutzman, T.W., Bowers, C.W., Brenner, K.A. and Irwin, L.L., 1995. Spherical densiometers produce biased estimators of forest canopy cover. Wildlife Soc. B., 23: 711-717.

De Frenne, P., Brunet, J., Shevtsova, A., Kolb, A., Graae, B.J., Chabrerie, O., Cousins, S.A.O., Decocq, G., De Schrijver, A., Diekmann, M., Gruwez, R., Heinken, T., Hermy, M., Nilsson, C., Stanton, S., Tack, W., Willaert, J. and Verheyen, K., 2011. Temperature effects on forest herbs assessed by warming and transplant experiments along a latitudinal gradient. Global Change Biol., 17(10): 3240-3253.

Engelbrecht, B.M.J. and Herz, H.M., 2001. Evaluation of different methods to estimate understorey light conditions in tropical forests. J. Trop. Ecology, 17(2): 207-224.

Engelhardt, M.J. and Anderson, R.C., 2011. Phenological niche separation from native species increases reproductive success of an invasive species: Alliaria petiolata (Brassicaceae) garlic mustard. J. Torrey Bot. Soc., 138(4): 418-433.

Fisher, J.I., Mustard, J.F. and Vadeboncoeur, M.A., 2006. Green leaf phenology at Landsat resolution: Scaling from the field to the satellite. Remote Sens. Environ., 100(2): 265279.

Frazer, G.W., Fournier, R.A., Trofymow, J.A. and Hall, R.J., 2001. A comparison of digital and film fisheye photography for analysis of forest canopy structure and gap light transmission. Agric. For. Meteorol., 109(4): 249-263.

Frazer, G.W., Trofymow, J.A. and Lertzman, K.P., 1997. A method for estimating canopy openness, effective leaf area index, and photosynthetically active photon flux density using hemispherical photography and computerized image analysis techniques. Nat. Res. Canada, Can. For. Serv. Pacific For. Cent. Inf. Re BC-X-373, pp 75.

Gendron, F., Messier, C. and Comeau, P.G., 1998. Comparison of various methods for estimating the mean growing season percent photosynthetic photon flux density in forests. Agric. For. Meteorol., 92(1): 55-70.

Giasson, M.A., Ellison, A.M., Bowden, R.D., Crill, P.M., Davidson, E.A., Drake, J.E., Frey, S.D., Hadley, J.L., Lavine, M., Melillo, J.M., Munger, J.W., Nadelhoffer, K.J., Nicoll, L., Ollinger, S.V., Savage, K.E., Steudler, P.A., Tang, J., Varner, R.K., Wofsy, S.C., Foster, D.R. and Finzi, A.C., 2013. Soil respiration in a northeastern US temperate forest: a 22-year synthesis. Ecosphere, 4(11): 1-28.

Glatthorn, J. and Beckschafer, P., 2014. Standardizing the protocol for hemispherical photographs: accuracy assessment of binarization algorithms. PLoS One, 9(11).

Gonsamo, A., D'Odorico, P. and Pellikka, P., 2013. Measuring fractional forest canopy element cover and openness - definitions and methodologies revisited. Oikos, 122(9): 1283-1291.

Hale, S.E. and Edwards, C., 2002. Comparison of film and digital hemispherical photography across a wide range of canopy densities. Agric. For. Meteorol., 112(1): 51-56.

Hamunyela, E., Verbesselt, J., Roerink, G. and Herold, M., 2013. Trends in Spring Phenology of Western European Deciduous Forests. Remote Sens., 5(12): 6159. 
Herbert, T.J., 1987. Area projections of fisheye photographic lenses. Agric. For. Meteorol., 39(23): 215-223.

Inoue, A., Yamamoto, K. and Mizoue, N., 2011. Comparison of automatic and interactive thresholding of hemispherical photography. J. For. Sci., 57: 78-87.

Inoue, A., Yamamoto, K., Mizoue, N. and Kawahara, Y., 2004. Effects of image quality, size and camera type on forest light environment estimates using digital hemispherical photography. Agric. For. Meteorol., 126(1-2): 89-97.

Jennings, S.B., Brown, N.D. and Sheil, D., 1999. Assessing forest canopies and understorey illumination: canopy closure, canopy cover and other measures. Forestry, 72(1): 59-73.

Jeong, S., Medvigy, D., Shevliakova, E. and Malyshev, S., 2013. Predicting changes in temperate forest budburst using continental-scale observations and models. Geophys. Res. Lett., 40(2): 359-364.

Jonckheere, I., Fleck, S., Nackaerts, K., Muys, B., Coppin, P., Weiss, M. and Baret, F., 2004. Review of methods for in situ leaf area index determination - Part I. Theories, sensors and hemispherical photography. Agric. For. Meteorol., 121(1-2): 19-35.

Jonckheere, I., Nackaerts, K., Muys, B. and Coppin, P., 2005. Assessment of automatic gap fraction estimation of forests from digital hemispherical photography. Agric. For. Meteorol., 132(1): 96-114.

Kay, M. and Wobbrock, J.O., 2016. ARTool: Aligned Rank Transform for Nonparametric Factorial ANOVAs. R package version 0.10.4, https://github.com/mjskay/ARTool.

Kim, H.J., Jung, J.B., Jang, Y.L., Sung, J.H. and Park, P.S., 2015. Effects of experimental early canopy closure on the growth and reproduction of spring ephemeral Erythronium japonicum in a montane deciduous forest. J. Plant Biol., 58(3): 164-174.

Kosmala, M., Crall, A., Cheng, R., Hufkens, K., Henderson, S. and Richardson, A.D., 2016. Season Spotter: Using Citizen Science to Validate and Scale Plant Phenology from Near-Surface Remote Sensing. Remote Sens., 8(9).

Leblanc, S.G., 2005. Digital Hemispherical Photography Manual (v. 1.2). Natural Resources Canada - Canada Centre for Remote Sensing, Saint-Hubert, Québec, 28 pp.

Lenth, R., 2017. emmeans: Estimated Marginal Means, aka Least-Squares Means. R package version 1.0, https://CRAN.R-project.org/package=emmeans.

Macfarlane, C., Hoffman, M., Eamus, D., Kerp, N., Higginson, S., McMurtrie, R. and Adams, M., 2007. Estimation of leaf area index in eucalypt forest using digital photography. Agric. For. Meteorol., 143(3): 176-188.

Machado, J.L. and Reich, P.B., 1999. Evaluation of several measures of canopy openness as predictors of photosynthetic photon flux density in deeply shaded conifer-dominated forest understory. Can. J. Forest Res., 29(9): 1438-1444.

Margalef, R., 1969. Diversity and stability: A practical proposal and a model of interdependence. In: G.M. Woodwell and H.H. Smith (Editors), Diversity and Stability in Ecological Systems, Brookhaven Symposium in Biology, No 22. Brookhaven National Laboratory, New York, pp. 25-37.

Mayer, A., 2010. Phenology and citizen science. Bioscience, 60(3): 172-175. 
Menzel, A. and Fabian, P., 1999. Growing season extended in Europe. Nature, 397(6721): 659659.

Menzel, A., Sparks, T.H., Estrella, N., Koch, E., Aasa, A., Ahas, R., Alm-Kubler, K., Bissolli, P., Braslavska, O., Briede, A., Chmielewski, F.M., Crepinsek, Z., Curnel, Y., Dahl, A., Defila, C., Donnelly, A., Filella, Y., Jatcza, K., Mage, F., Mestre, A., Nordli, O., Penuelas, J., Pirinen, P., Remisova, V., Scheifinger, H., Striz, M., Susnik, A., Van Vliet, A.J.H., Wielgolaski, F.E., Zach, S. and Zust, A., 2006. European phenological response to climate change matches the warming pattern. Global Change Biol., 12(10): 1969-1976.

Pellikka, P., 2001. Application of vertical skyward wide-angle photography and airborne video data for phenological studies of beech forests in the German Alps. Int. J. Remote Sens., 22(14): 2675-2700.

Promis, A., Caldentey, J. and Cruz, G., 2012. Evaluating the usefulness of hemispherical photographs as a means to estimate photosynthetic photon flux density during a growing season in the understorey of Nothofagus pumilio forests. Plant Biosyst., 146(1): 237-243.

Promis, A., Gärtner, S.M., Butler-Manning, D., Durán-Rangel, C., Rief, A., Cruz, G. and Hernández, L., 2011. Comparison of four different programs for the analysis of hemispherical photographs using parameters of canopy structure and solar radiation transmittance. Waldokologie, 11: 19-33.

R Core Team, 2016. R: A language and environment for statistical computing. R Foundation for Statistical Computing, Vienna, Austria

Rich, P.M., 1989. A manual for analysis of hemispherical canopy photography. Technical Report, Los Alamos National Lab., NM, USA.

Rich, P.M., 1990. Characterizing plant canopies with hemispherical photographs. Remote Sens. Rev., 5(1): 13-29.

Rich, P.M., Wood, J., Vieglais, D.A., Burek, K. and Webb, N., 1999. User manual for HemiView version 2.1. Delta-T Devices, United Kingdom.

Richardson, A.D., Bailey, A.S., Denny, E.G., Martin, C.W. and O'Keefe, J., 2006. Phenology of a northern hardwood forest canopy. Global Change Biol., 12(7): 1174-1188.

Richardson, A.D., Keenan, T.F., Migliavacca, M., Ryu, Y., Sonnentag, O. and Toomey, M., 2013. Climate change, phenology, and phenological control of vegetation feedbacks to the climate system. Agric. For. Meteorol., 169: 156-173.

Roberts, A.M.I., Tansey, C., Smithers, R.J. and Phillimore, A.B., 2015. Predicting a change in the order of spring phenology in temperate forests. Global Change Biol., 21(7): 2603-2611.

Roxburgh, J.R. and Kelly, D., 1995. Uses and limitations of hemispherical photography for estimating forest light environments. N. Z. J. Ecol., 19(2): 213-217.

Rueden, C., Dietz, C., Horn, M., Schindelin, J., Northan, B., Berthold, M., Eliceiri, K. , 2016. ImageJ Ops [Software]. http://imagej.net/Ops.

Ryu, Y., Nilson, T., Kobayashi, H., Sonnentag, O., Law, B.E. and Baldocchi, D.D., 2010. On the correct estimation of effective leaf area index: Does it reveal information on clumping effects? Agric. For. Meteorol., 150(3): 463-472. 
Ryu, Y., Verfaillie, J., Macfarlane, C., Kobayashi, H., Sonnentag, O., Vargas, R., Ma, S. and Baldocchi, D.D., 2012. Continuous observation of tree leaf area index at ecosystem scale using upward-pointing digital cameras. Remote Sens. Environ., 126: 116-125.

Thompson, R. and Clark, R.M., 2008. Is spring starting earlier? Holocene, 18(1): 95-104.

University of New Hampshire, 2017. Picture Post. https://picturepost.unh.edu/index.jsp Accessed: December 18, 2017.

Vales, D.J. and Bunnell, F.L., 1988. Comparison of methods for estimating forest overstory cover: differences among techniques. Can. J. Forest Res., 20(1): 101-107.

Van Couwenberghe, R., Collet, C., Lacombe, E. and Gegout, J.C., 2011. Abundance response of western European forest species along canopy openness and soil pH gradients. For. Ecol. Manage., 262(8): 1483-1490.

Vitasse, Y., Francois, C., Delpierre, N., Dufrêne, E., Kremer, A., Chuine, I. and Delzon, S., 2011. Assessing the effects of climate change on the phenology of European temperate trees. Agric. For. Meteorol., 151(7): 969-980.

Wang, S., Yang, B., Yang, Q., Lu, L., Wang, X. and Peng, Y., 2016. Temporal Trends and Spatial Variability of Vegetation Phenology over the Northern Hemisphere during 1982-2012. PLoS One, 11(6): e0157134.

Weiss, M., Baret, F., Smith, G.J., Jonckheere, I. and Coppin, P., 2004. Review of methods for in situ leaf area index (LAI) determination. Agric. For. Meteorol., 121(1): 37-53.

White, K., Pontius, J. and Schaberg, P., 2014. Remote sensing of spring phenology in northeastern forests: A comparison of methods, field metrics and sources of uncertainty. Remote Sens. of Environ., 148: 97-107.

White, M.A., De Beurs, K.M., Didan, K., Inouye, D.W., Richardson, A.D., Jensen, O.P., O'Keefe, J., Zhang, G., Nemani, R.R., Van Leeuwen, W.J.D., Brown, J.F., De Wit, A., Schaepman, M., Lin, X., Dettinger, M., Bailey, A.S., Kimball, J., Schwartz, M.D., Baldocchi, D.D., Lee, J.T. and Lauenroth, W.K., 2009. Intercomparison, interpretation, and assessment of spring phenology in North America estimated from remote sensing for 1982-2006. Global Change Biol., 15(10): 2335-2359.

Whitmore, T.C., Brown, N.D., Swaine, M.D., Kennedy, D., Goodwin-Bailey, C.I. and Gong, W.K., 1993. Use of hemispherical photographs in forest ecology: measurement of gap size and radiation totals in a Bornean tropical rain forest. J. Trop. Ecology, 9(2): 131-151.

Willis, C.G., Ruhfel, B.R., Primack, R.B., Miller-Rushing, A.J., Losos, J.B. and Davis, C.C., 2010. Favorable climate change response explains non-native species' success in Thoreau's Woods. PLoS One, 5(1).

Wobbrock, J.O., Findlater, L., Gergle, D. and Higgins, J.J., 2011. The Aligned Rank Transform for nonparametric factorial analyses using only ANOVA procedures. , ACM Conference on Human Factors in Computing Systems (CHI '11), Vancouver, British Columbia (May 7-12, 2011). ACM Press, New York, pp. 143-146.

Woodgate, W., Jones, S.D., Suarez, L., Hill, M.J., Armston, J.D., Wilkes, P., Soto-Berelov, M., Haywood, A. and Mellor, A., 2015. Understanding the variability in ground-based methods for retrieving canopy openness, gap fraction, and leaf area index in diverse forest systems. Agric. For. Meteorol., 205: 83-95. 
761

762

763

764

765

766

767

768

769

770

771

772

Wu, X. and Liu, H., 2013. Consistent shifts in spring vegetation green-up date across temperate biomes in China, 1982-2006. Global Change Biol., 19(3): 870-880.

Yuste, J.C., Janssens, I.A., Carrara, A. and Ceulemans, R., 2004. Annual Q(10) of soil respiration reflects plant phenological patterns as well as temperature sensitivity. Global Change Biol., 10(2): 161-169.

Zhang, X., Friedl, M.A., Schaaf, C.B., Strahler, A.H., Hodges, J.C.F., Gao, F., Reed, B.C. and Huete, A., 2003. Monitoring vegetation phenology using MODIS. Remote Sens. Environ., 84(3): 471-475.

Zhang, Y.Q., Chen, J.M. and Miller, J.R., 2005. Determining digital hemispherical photograph exposure for leaf area index estimation. Agric. For. Meteorol., 133(1-4): 166-181.

Zhao, K.N. and He, F.L., 2016. Estimating light environment in forests with a new thresholding method for hemispherical photography. Can. J. Forest Res., 46(9): 1103-1110. 


\section{Tables}

775

\begin{tabular}{|c|c|c|c|c|c|c|}
\hline Site & $\begin{array}{l}\text { Size } \\
\text { (ha) }\end{array}$ & $\begin{array}{l}\text { Stand density } \\
\text { (trees/ha) }\end{array}$ & $\begin{array}{l}\text { Average } \\
\text { tree height } \\
\text { (m) }\end{array}$ & Aspect & $\begin{array}{l}\text { Dominant canopy } \\
\text { species }\end{array}$ & $\begin{array}{l}\text { Dominant shrub layer } \\
\text { species }\end{array}$ \\
\hline $\begin{array}{l}\text { Hardwick Wood } \\
\left(50^{\circ} 22^{\prime} \mathrm{N}, 4^{\circ} 4^{\prime} \mathrm{W}\right)\end{array}$ & 22 & 1360 & 16 & Flat & $\begin{array}{l}\text { Acer pseudoplatanus, } \\
\text { Fraxinus excelsior }\end{array}$ & $\begin{array}{l}\text { Acer pseudeoplatanus, Ulmus } \\
\text { sp. }\end{array}$ \\
\hline $\begin{array}{l}\text { Hunshaw Wood } \\
\left(50^{\circ} 55^{\prime} \mathrm{N}, 4^{\circ} 7^{\prime} \mathrm{W}\right)\end{array}$ & 18 & 556 & 30 & $S$ & $\begin{array}{l}\text { Quercus robur with Fagus } \\
\text { sylvatica sub-canopy }\end{array}$ & $\begin{array}{l}\text { Corylus avellana, Sorbus } \\
\text { aucuparia }\end{array}$ \\
\hline $\begin{array}{l}\text { Newton Mill } \\
\left(50^{\circ} 52^{\prime} \mathrm{N}, 4^{\circ} 15^{\prime} \mathrm{W}\right)\end{array}$ & 25 & 456 & 35 & NE & Quercus robur & $\begin{array}{l}\text { Corylus avellana, Fagus } \\
\text { sylvatica }\end{array}$ \\
\hline $\begin{array}{l}\text { Whitleigh Wood } \\
\left(50^{\circ} 25^{\prime} \mathrm{N}, 4^{\circ} 8^{\prime} \mathrm{W}\right)\end{array}$ & 20 & 1111 & 27 & $N$ & $\begin{array}{l}\text { Quercus robur and Betula } \\
\text { pendula }\end{array}$ & $\begin{array}{l}\text { Corylus avellana, Fagus } \\
\text { sylvatica, Acer pseudoplatanus }\end{array}$ \\
\hline
\end{tabular}

776 Table 1. Site descriptions of woodlands used to compare methods for estimating

777 canopy openness. All sites were located in Devon, England. 


\begin{tabular}{ccccccccccc} 
Method & \multicolumn{2}{c}{ All seasons } & \multicolumn{2}{c}{ Spring } & \multicolumn{2}{c}{ Summer } & \multicolumn{2}{c}{ Autumn } & \multicolumn{2}{c}{ Winter } \\
& $\boldsymbol{R}^{2}$ & $\boldsymbol{p}$ & $\boldsymbol{R}^{2}$ & $\boldsymbol{p}$ & $\boldsymbol{R}^{2}$ & $\boldsymbol{p}$ & $\boldsymbol{R}^{2}$ & $\boldsymbol{p}$ & $\boldsymbol{R}^{2}$ & $\boldsymbol{p}$ \\
Hemispherical photo (ImageJ) & 0.96 & $<0.001$ & 0.85 & $<0.001$ & 0.77 & $<0.001$ & 0.94 & $<0.001$ & 0.69 & $<0.001$ \\
Smartphone fisheye photo (HemiView) & 0.89 & $<0.001$ & 0.83 & $<0.001$ & 0.67 & $<0.001$ & 0.79 & $<0.001$ & 0.05 & 0.300 \\
Smartphone fisheye photo (ImageJ) & 0.84 & $<0.001$ & 0.74 & $<0.001$ & 0.76 & $<0.001$ & 0.66 & $<0.001$ & 0.08 & 0.170 \\
Smartphone photo (overhead) & 0.85 & $<0.001$ & 0.57 & 0.002 & 0.43 & $<0.001$ & 0.69 & $<0.001$ & 0.04 & 0.380 \\
Smartphone photo (average of 4) & 0.81 & $<0.001$ & 0.15 & 0.410 & 0.60 & $<0.001$ & 0.72 & $<0.001$ & 0.02 & 0.490 \\
Canopy scope (overhead) & 0.51 & $<0.001$ & 0.24 & 0.240 & 0.01 & 0.170 & 0.41 & $<0.001$ & 0.00 & 0.820 \\
Canopy scope (largest gap) & 0.52 & $<0.001$ & 0.2 & 0.029 & 0.20 & 0.030 & 0.33 & 0.003 & 0.00 & 0.850 \\
Canopy scope (average of 4) & 0.55 & $<0.001$ & 0.31 & 0.005 & 0.18 & 0.040 & 0.55 & $<0.001$ & 0.00 & 0.910 \\
Visual estimation (overhead) & 0.39 & $<0.001$ & 0.01 & 0.740 & 0.05 & 0.280 & 0.31 & 0.005 & 0.06 & 0.260 \\
Visual estimation (average of 4) & 0.52 & $<0.001$ & 0.03 & 0.460 & 0.20 & 0.029 & 0.51 & $<0.001$ & 0.04 & 0.350
\end{tabular}

778 Table 2. Proportion of variation explained $\left(R^{2}\right)$ and statistical significance $(p)$ for

779 relationships between hemispherical photography analysed with HemiView and

780 alternative methods. Relationships were considered separately for each season, as well

781 as across all seasons together. 


\begin{tabular}{ccccccccc} 
Method & \multicolumn{2}{c}{ Hardwick } & \multicolumn{2}{c}{ Hunshaw } & \multicolumn{2}{c}{ Newton Mill } & \multicolumn{2}{c}{ Whitleigh } \\
& $\boldsymbol{R}^{2}$ & $\boldsymbol{p}$ & $\boldsymbol{R}^{2}$ & $\boldsymbol{p}$ & $\boldsymbol{R}^{2}$ & $\boldsymbol{p}$ & $\boldsymbol{R}^{2}$ & $\boldsymbol{p}$ \\
Hemispherical photo (ImageJ) & 0.97 & $<0.001$ & 0.85 & $<0.001$ & 0.98 & $<0.001$ & 0.81 & $<0.001$ \\
Smartphone photo fisheye (HemiView) & 0.95 & $<0.001$ & 0.86 & $<0.001$ & 0.86 & $<0.001$ & 0.86 & $<0.001$ \\
Smartphone photo fisheye (ImageJ) & 0.84 & $<0.001$ & 0.80 & $<0.001$ & 0.81 & $<0.001$ & 0.86 & $<0.001$ \\
Smartphone photo (overhead) & 0.88 & $<0.001$ & 0.78 & $<0.001$ & 0.68 & $<0.001$ & 0.85 & $<0.001$ \\
Smartphone photo (average of 4) & 0.92 & $<0.001$ & 0.93 & $<0.001$ & 0.70 & $<0.001$ & 0.85 & $<0.001$ \\
Canopy scope (overhead) & 0.47 & 0.002 & 0.08 & 0.260 & 0.68 & $<0.001$ & 0.19 & 0.072 \\
Canopy scope (largest gap) & 0.42 & 0.004 & 0.22 & 0.049 & 0.73 & $<0.001$ & 0.12 & 0.160 \\
Canopy scope (average of 4) & 0.39 & 0.005 & 0.25 & 0.034 & 0.75 & $<0.001$ & 0.16 & 0.100 \\
Visual estimation (overhead) & 0.42 & 0.004 & 0.1 & 0.200 & 0.60 & $<0.001$ & 0.01 & 0.630 \\
Visual estimation (average 4) & 0.47 & 0.002 & 0.2 & 0.063 & 0.67 & $<0.001$ & 0.01 & 0.740
\end{tabular}

782 Table 3. Proportion of variation explained $\left(R^{2}\right)$ and statistical significance $(p)$ for

783 relationships at each woodland site between estimates of canopy openness from

784 hemispherical photography analysed with HemiView versus estimates from other

785 methods. Photographs were included from spring, summer and autumn, but not winter. 


\section{Figures}

787 Fig. 1. Canopy openness estimates from hemispherical photography with HemiView

$788(\mathrm{HP}+\mathrm{HV})$ compared with estimates from hemispherical photography with ImageJ

$789(\mathrm{HP}+\mathrm{IJ})$, smartphone fisheye photography with HemiView $(\mathrm{SP}+\mathrm{HV})$, and smartphone

790 fisheye photography with ImageJ $(\mathrm{SP}+\mathrm{IJ})$. Figs A-C. Overall relationships across all

791 seasons. $R^{2}$ and statistical significance of these relationships is presented in Table 2.

792 Figs D-F. Separate relationships for each growing season (light green $=$ spring, dark

793 green = summer, dark red = autumn).

794 Fig. 2. Site canopy openness estimates from hemispherical photography with HemiView

$795(\mathrm{HP}+\mathrm{HV})$ compared with estimates from (A) hemispherical photography with ImageJ

796 (HP+IJ), (B) smartphone fisheye photography with HemiView (SP+HV), and (C)

797 smartphone fisheye photography with ImageJ $(\mathrm{SP}+\mathrm{IJ}) \cdot R^{2}$ and statistical significance of

798 these relationships is presented in Table 3. Relationships are shown for each site (red

$799=$ Hardwick, green $=$ Hunshaw, blue $=$ Newton Mill, grey $=$ Whitleigh $)$.

800 Fig. 3. Comparison of estimates of canopy openness using three different models of

801 smartphone in three canopy densities. Every canopy density $\mathrm{x}$ phone combination was

802 based on 22 photographs, each taken by a different user. The median is shown as a

803 horizontal line, the box represents values within the $25-75 \%$ quartiles, and the error

804 bars show the minimum and maximum values. Means sharing a letter were not

805 significantly different according to post hoc contrasts using estimated marginal means. 

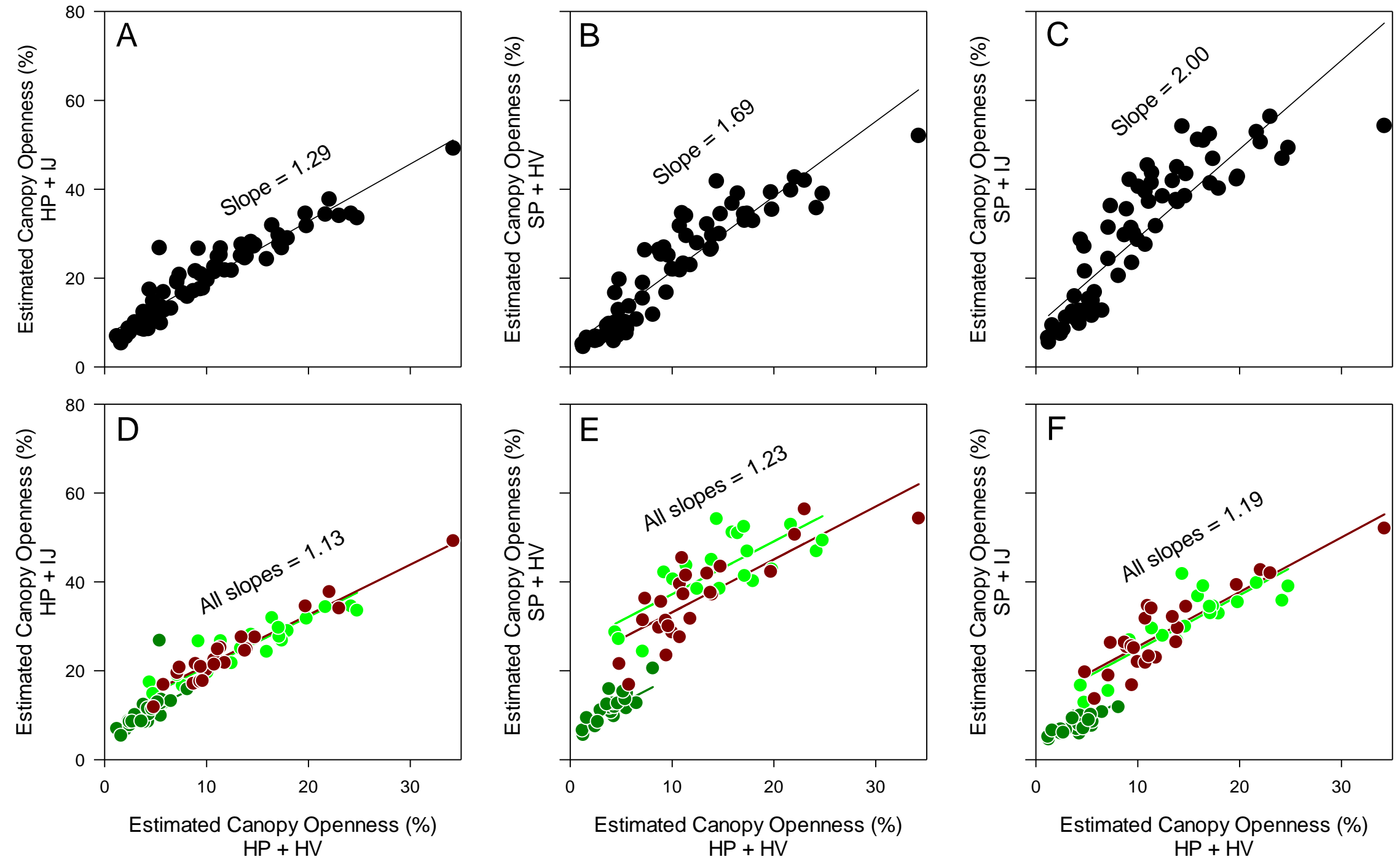
809 Fig. 2
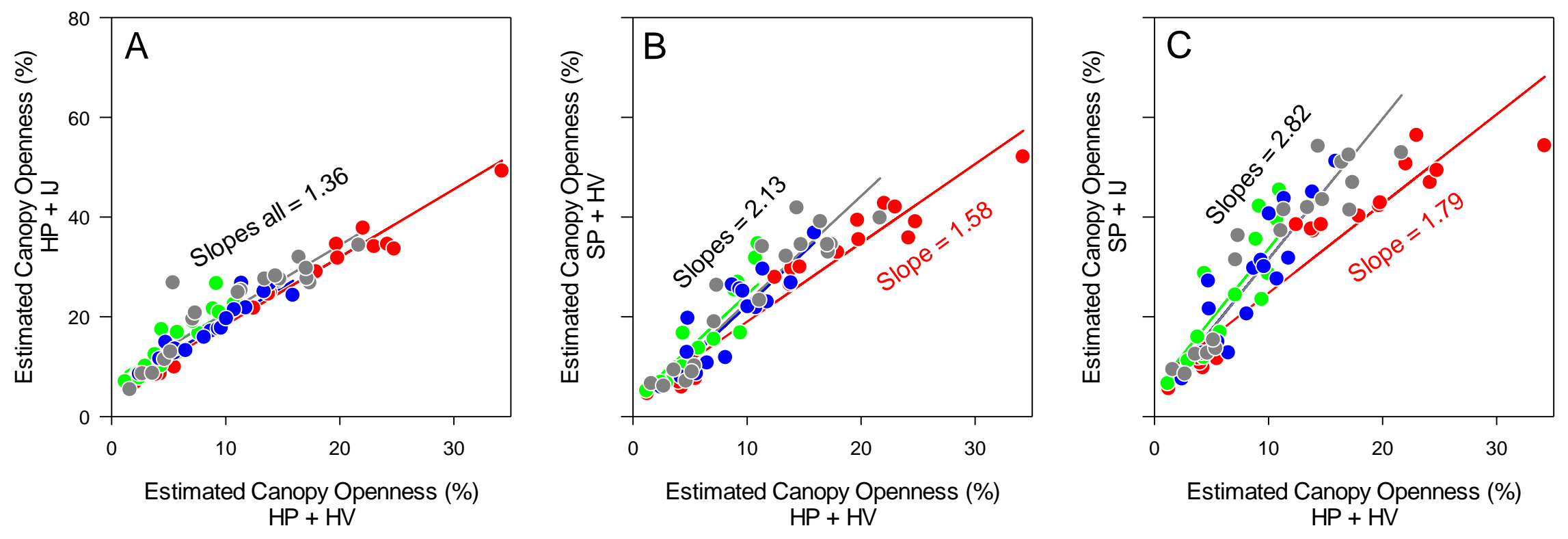
811 Fig. 3

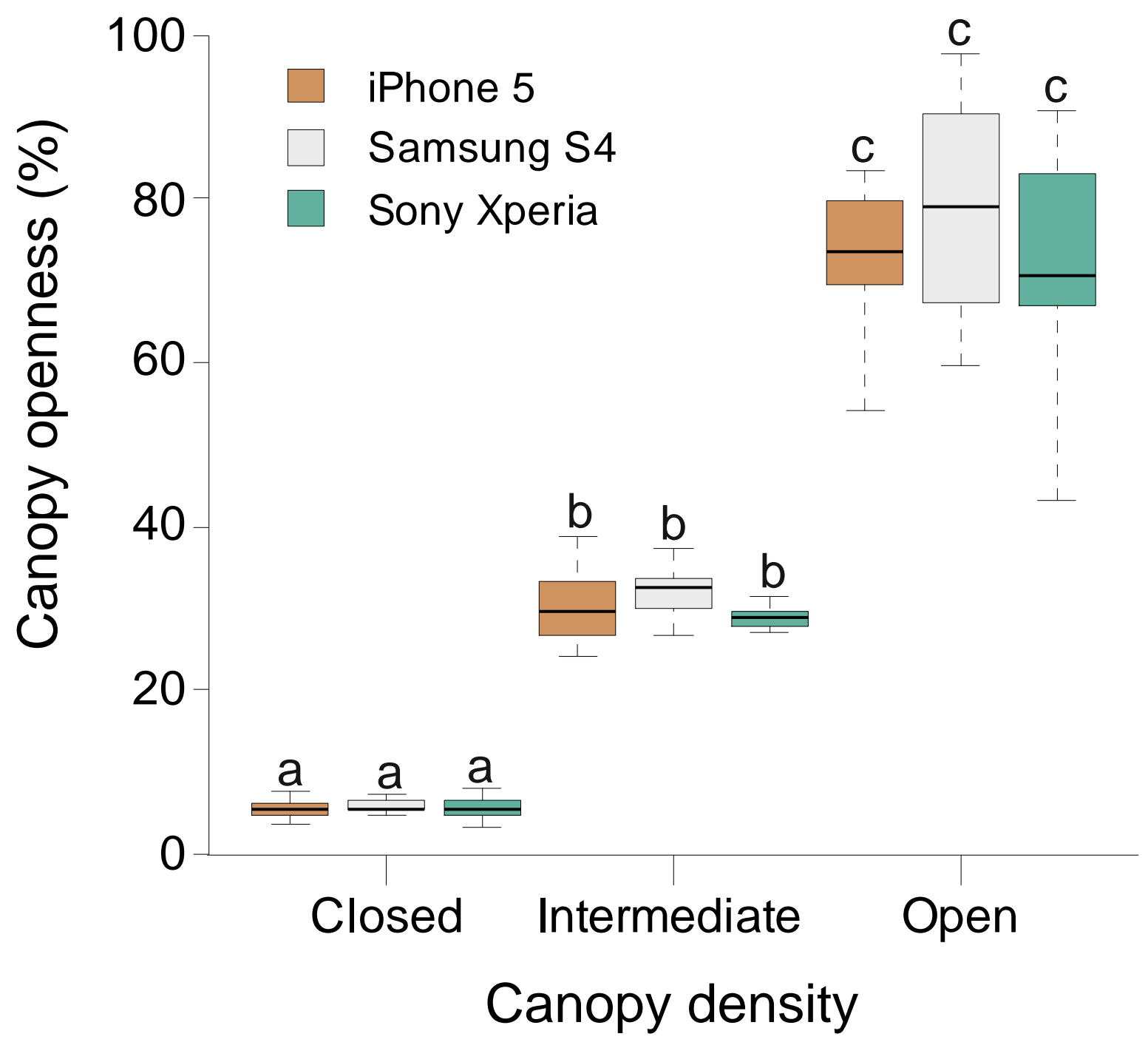

